\title{
Quad Trim Winding Interconnection on 21Q40 Half Cell Wiring Diagrams
}

\author{
BNL/SNS Technical Note \\ No. 136 \\ R. F. Lambiase \\ June 2, 2004
}

Collider-Accelerator Department Brookhaven National Laboratory

Upton, New York 11973 


\section{Overview}

I have reviewed seven wiring diagrams, all relating to $21 \mathrm{Q} 40$ installations. The drawings are $5300074,081,082,086,099,100$, and 129 . The trim wiring on all these drawings is correct for the depiction of the winding direction shown on the drawings.

\section{$\underline{\text { Methods }}$}

SNS Tech Note 119 gives us the pole definition for "A" polarity for a normal quad when looking at the lead end of the magnet. This is shown in Figure 1. The lead end is defined by where the main winding leads emerge. The terminal blocks are on the opposite end, so when viewing the terminals blocks for the trim windings, the pole definitions are mirror images. This is shown in Figure 2.

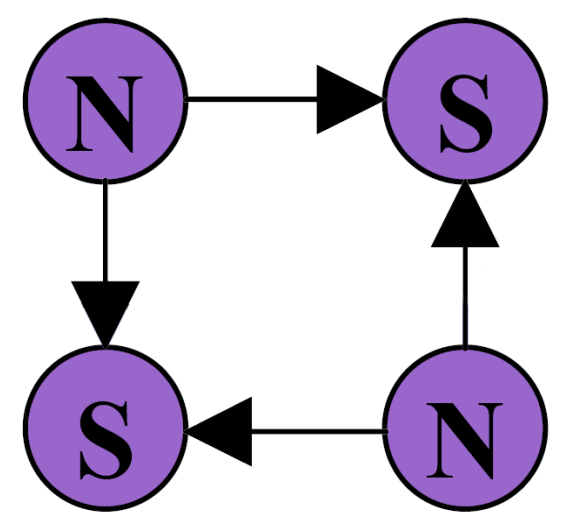

Figure 1 - Lead End, “A” Polarity

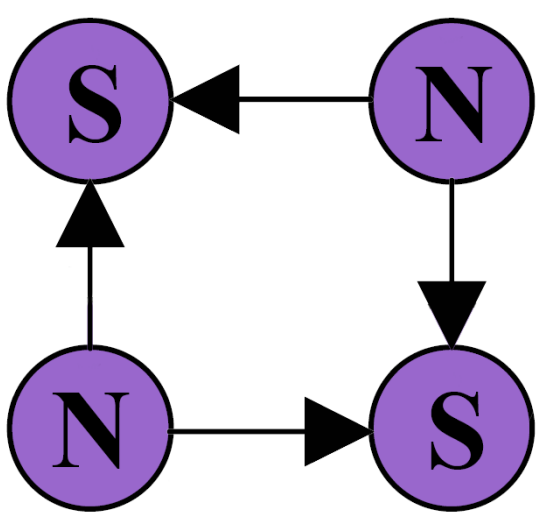

Figure 2 - Non-lead End, "A” Polarity

With a correct interconnection, a positive current entering terminal 1 will produce an "A" Polarity. I checked the drawings by marking up the relevant portion of each. The results are attached as a reference.

\section{Limitations}

For this drawing update, no coil drawings were changed. It is assumed by the drawing set that the person attaching the trim leads to the terminals will know how to do so without identification of the leads on the coil winding diagram. 


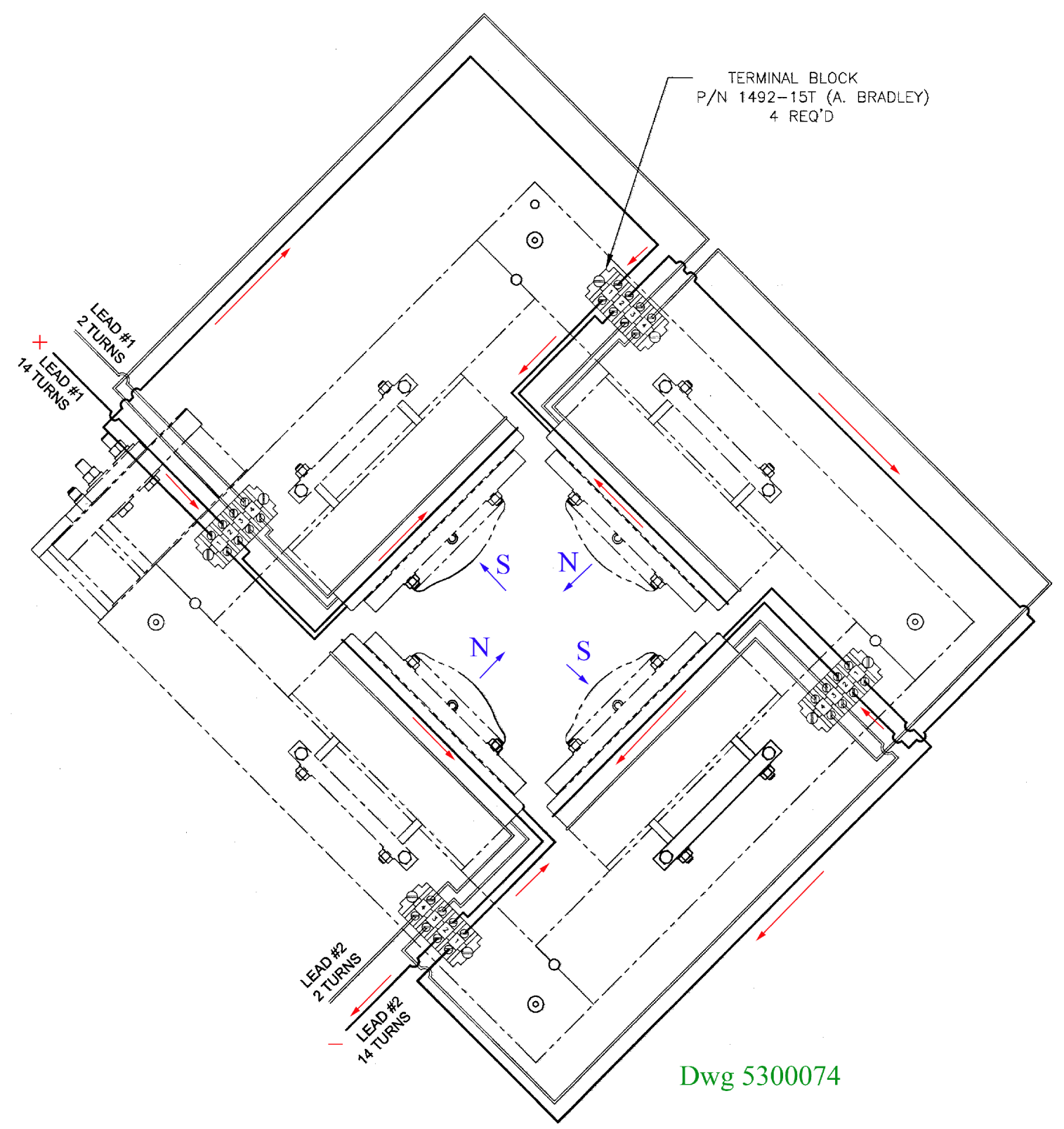

TRIM COILS WIRING DIAGRAM OF QUAD 21Q40 VIEW TOWARD DIPOLE 


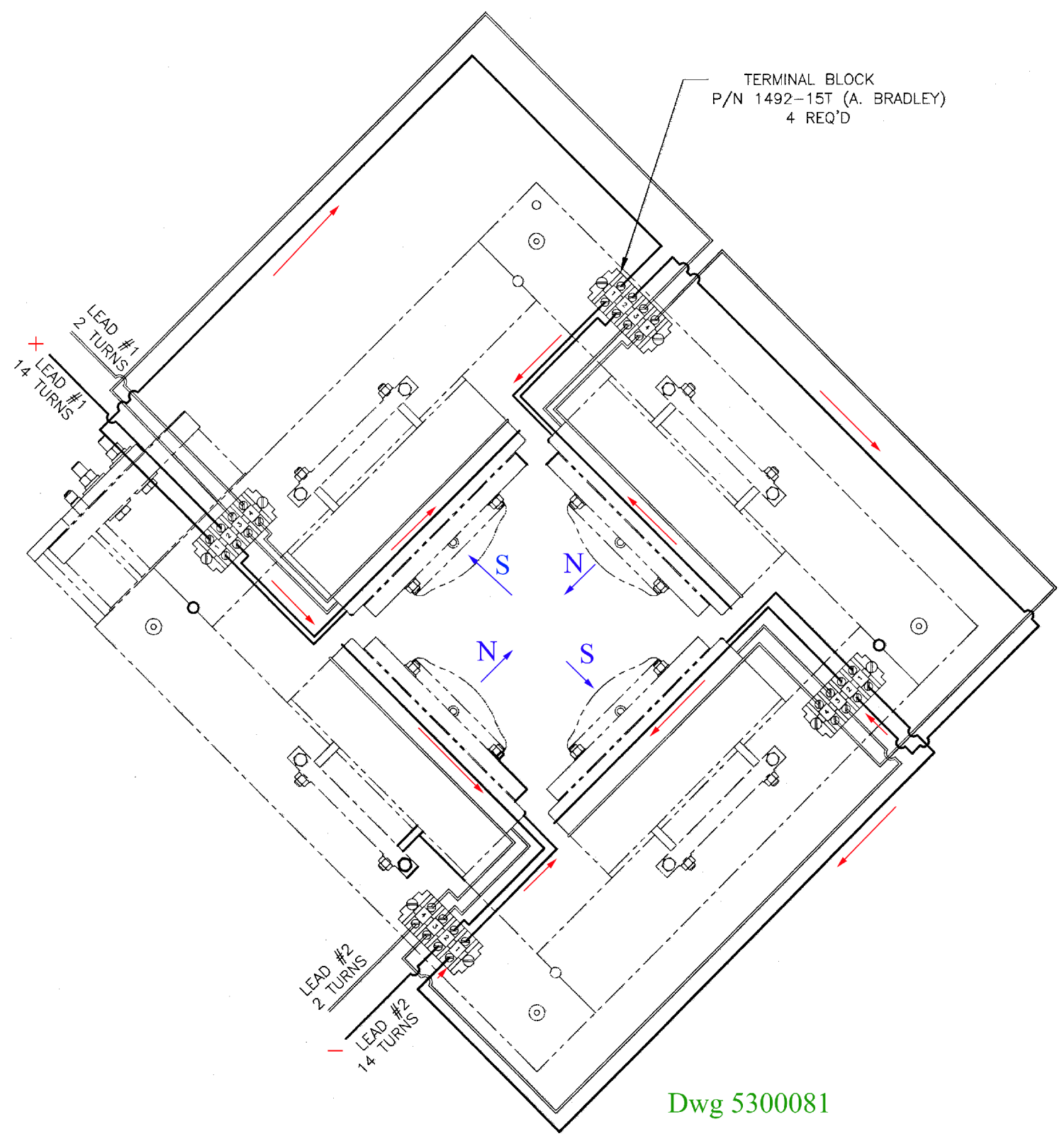

TRIM COILS WIRING DIAGRAM OF QUAD 21 Q40

VIEW TOWARD DIPOLE 


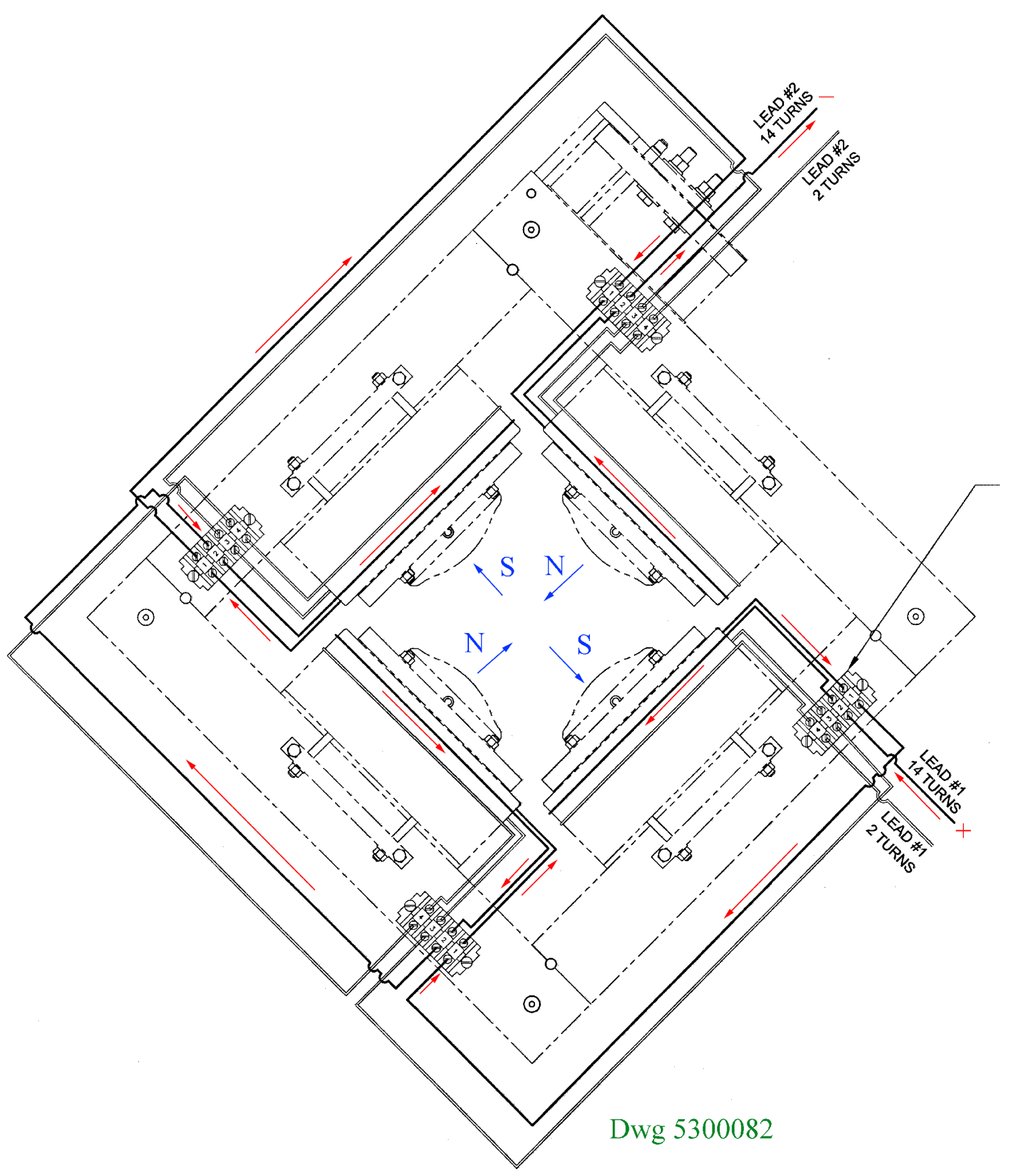

TRIM COILS WIRING DIAGRAM OF QUAD 21Q40

VIEW TOWARD DIPOLE 


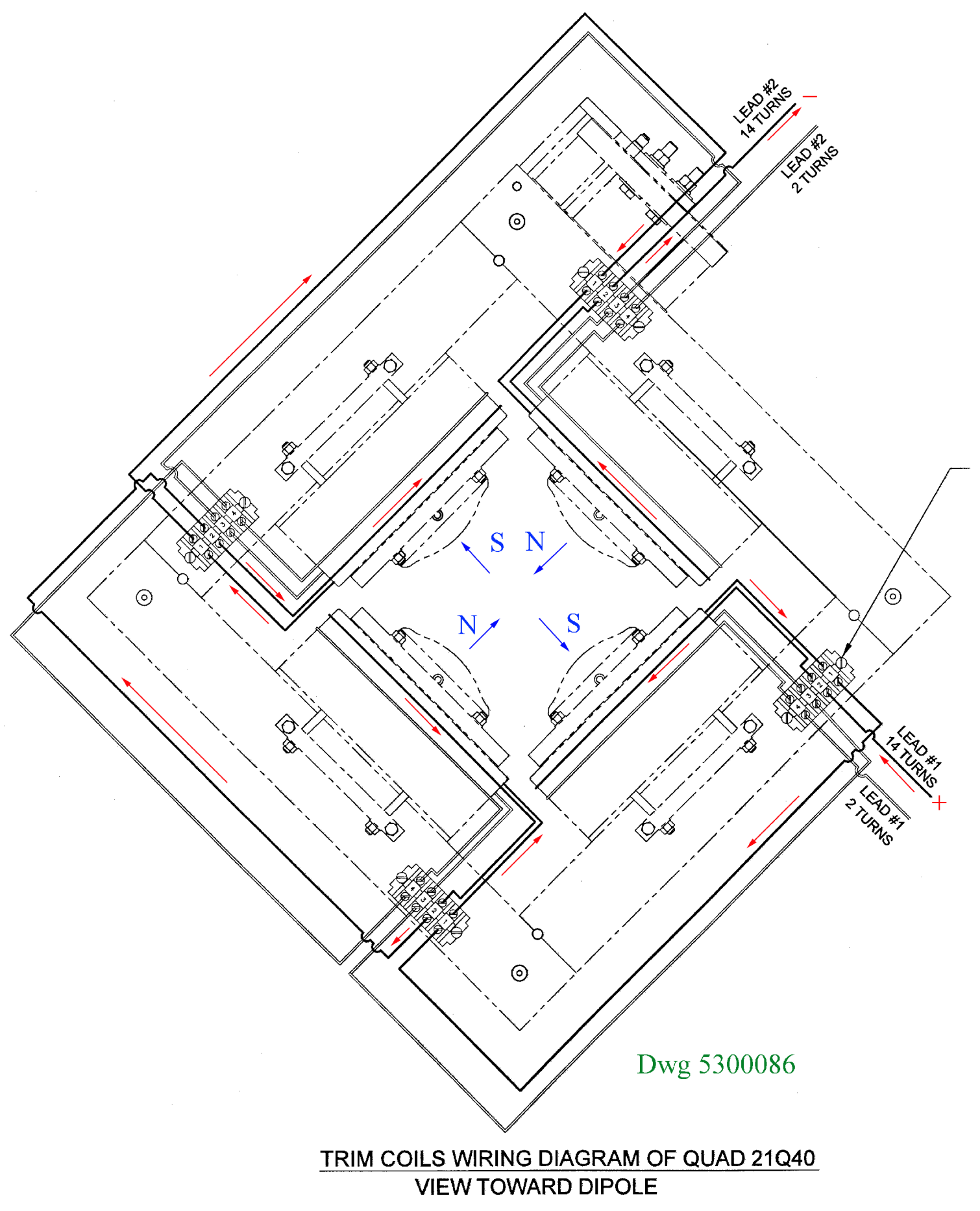




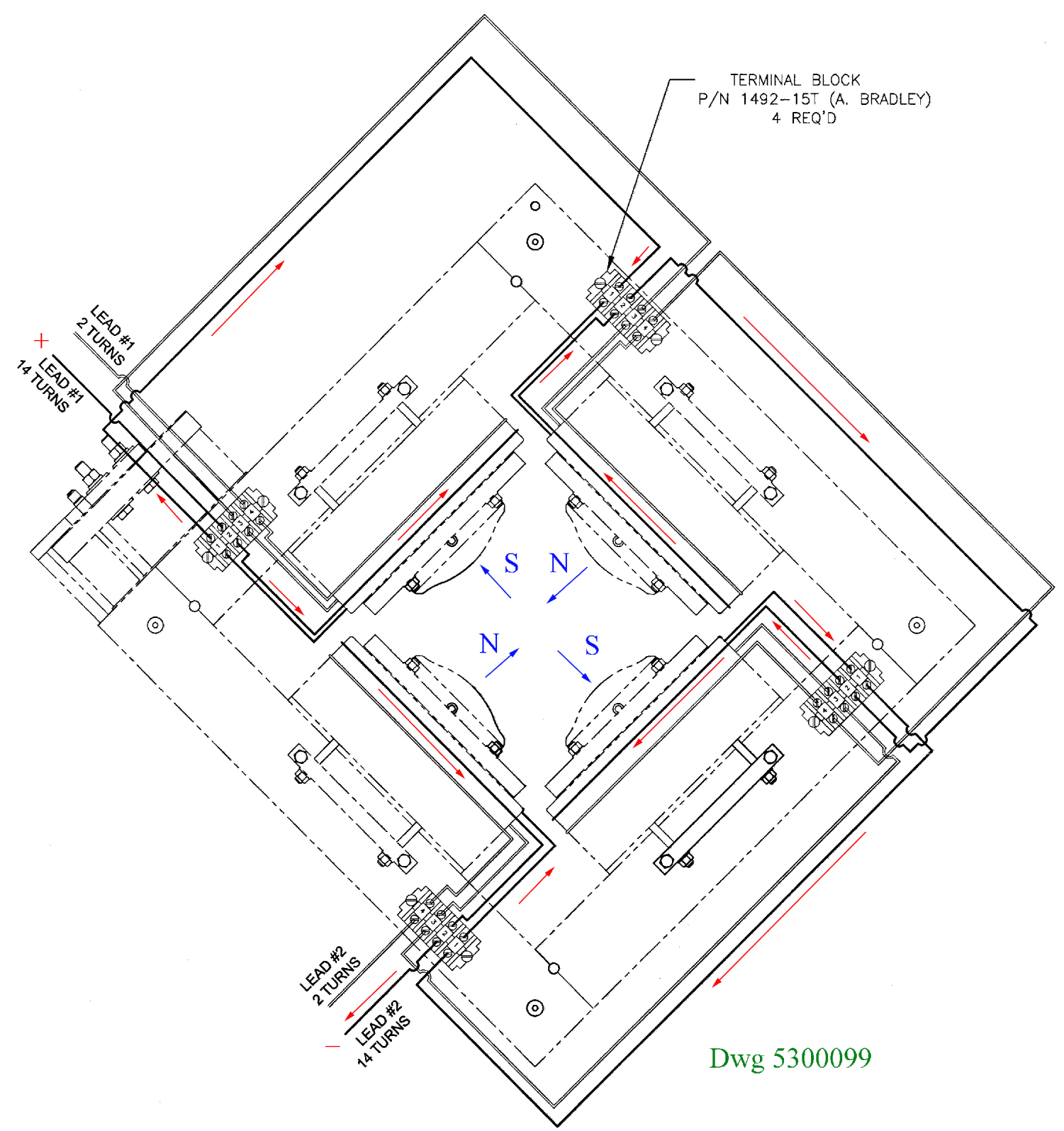

TRIM COILS WIRING DIAGRAM OF QUAD 21Q40

VIEW TOWARD DIPOLE 


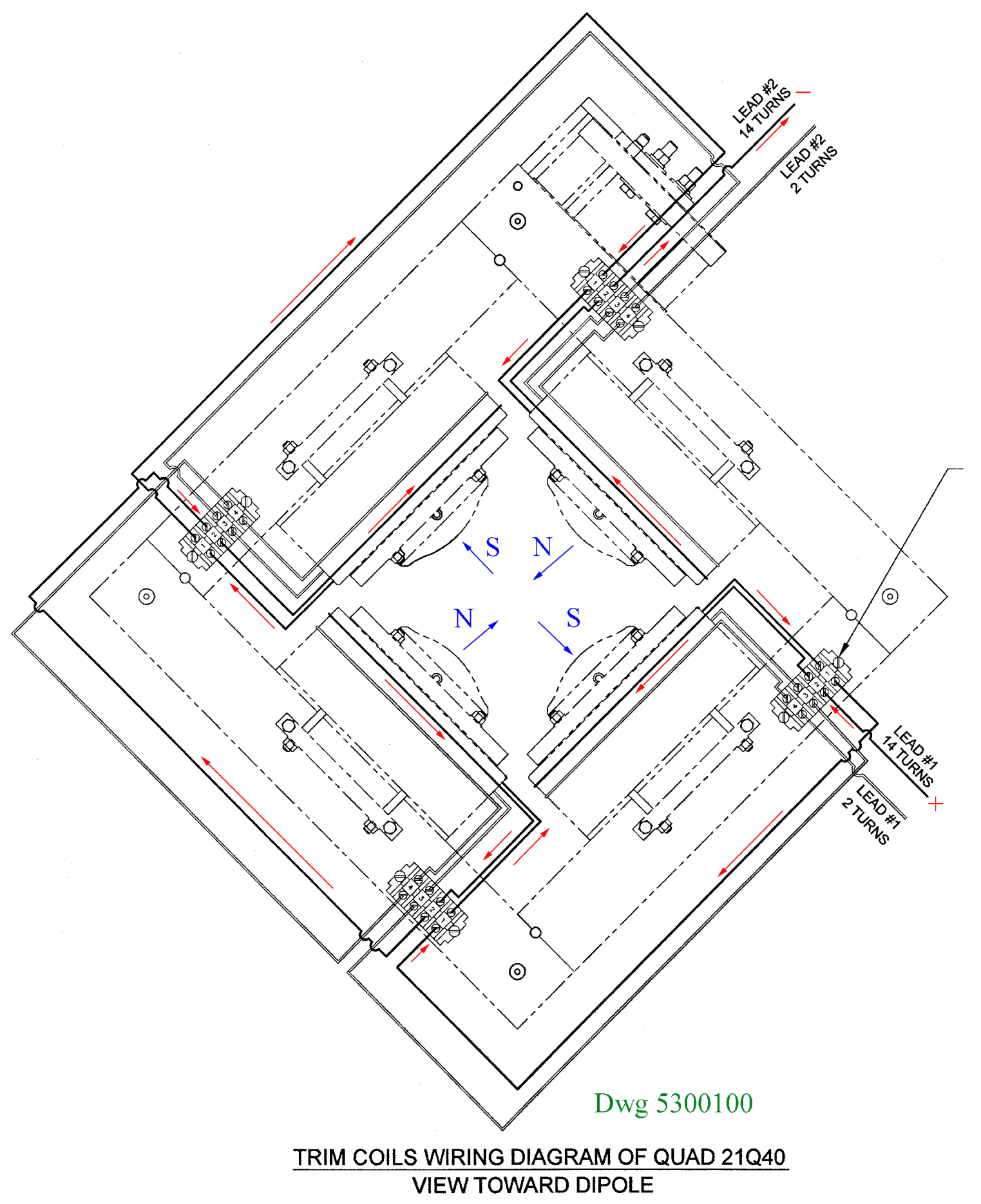




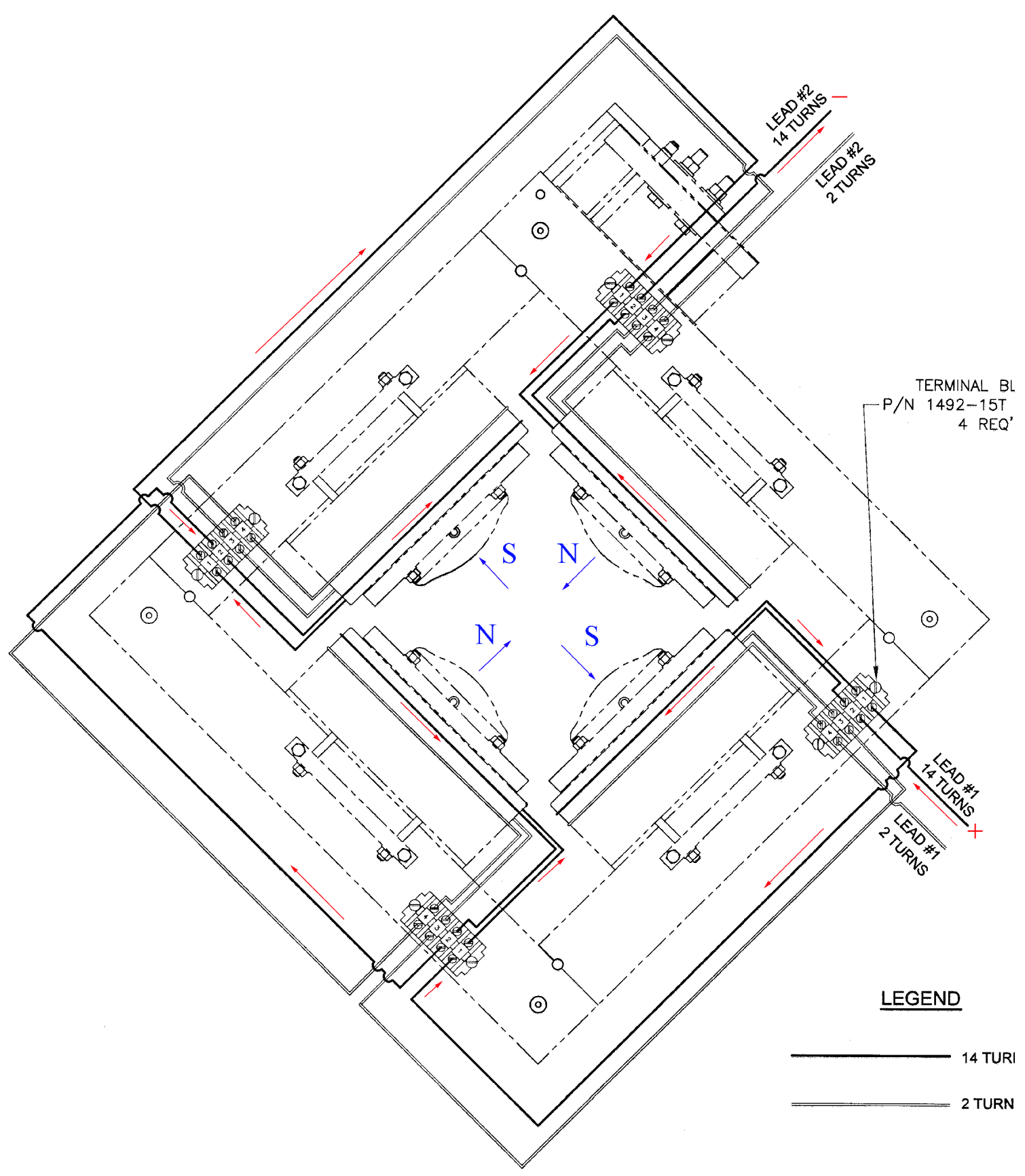

Dwg 5300129

TRIM COILS WIRING DIAGRAM OF QUAD 21Q40 VIEW LOOKING AT NON-LEAD END 